\title{
Manner-of-speaking that-complements as close apposition structures
}

\author{
Carlos de Cuba*
}

\begin{abstract}
An elusive property of that-clauses following manner-of-speaking verbs is that they do not behave like that-clauses following other non-factive verbs when it comes to the availability of $w h$-extraction, main clause phenomena and complementizer drop. Non-factive that-clauses allow wh-extraction, main clause phenomena and complementizer drop, but manner-of-speaking that-clauses resist them. In addition, the behavior of manner-of-speaking that-clauses patterns with noun complement clauses and that-clauses following the pronoun it. In this paper, I argue that the referential and adjunct status of manner-of-speaking that-clauses, noun complement clauses and that-clauses following the pronoun it is responsible for their shared restrictions on $w h$-extraction, main clause phenomena and complementizer drop. Specifically, I argue all three of these that-clauses are referential adjuncts in a close apposition relationship with a nominal object.
\end{abstract}

Keywords. manner-of-speaking verbs; that-clauses; wh-extraction; complementizer drop; main clause phenomena; object extraposition; close apposition; referentiality

1. Introduction: An elusive property of that-clauses which follow manner-of-speaking verbs (whisper, mutter, groan, etc.) is that they do not behave like complements to other non-factive verbs (say, think, believe, etc.) when it comes to the availability of $w h$-extraction, main clause phenomena and complementizer drop. ${ }^{1}$ Non-factive that-clauses (1) allow wh-extraction, main clause phenomena and complementizer drop while manner-of-speaking that-clauses (MoSCC) (2) resist them. Instead, MoSCCs pattern with noun complement clauses (NCCs) (3), and it + that-clause constructions (ICCs) (4), which also resist $w h$-extraction, main clause phenomena and complementizer drop.

\section{Non-factive:}

(1) a. Who did Barney say that Wilma was dating $t$ ?

b. Barney said that this man Wilma was dating $t$.

c. Barney said (that) Wilma was dating Fred.

\section{Manner-of-speaking:}

(2) a. * Who did Barney whisper that Wilma was dating $t$ ?

b. *Barney whispered that this man Wilma was dating $t$.

c. Barney whispered *(that) Wilma was dating Fred.

\section{Noun complement clause:}

(3) a. * Who did Barney repeat the claim that the government lied to $t$ ?

b. *Barney repeated the claim that this man Wilma was dating $t$.

c. the claim *(that) the government lied to the press

\footnotetext{
* Thanks to audiences at The Penn Linguistics Conference (PLC 41) at the University of Pennsylvania, the Subordinate Clauses in Generative Linguistics Workshop at University College London and LSA 2018 in Salt Lake City for helpful questions and comments on previous versions of this work. Author: Carlos de Cuba, Kingsborough Community College - CUNY (carlos.decuba@kbcc.cuny.edu).

${ }^{1}$ I use the terms factive and non-factive at this point for expository reasons only. Following de Cuba \& Ürögdi (2009), I replace these terms with referential and non-referential in section 3 below.
} 


\section{It + that-clause:}

(4) a. * Who did Barney resent it that the government lied to $t$ ?

b. * Barney resented it that this man Wilma was dating $t$.

c. Wilma resents it *(that) the government lied.

In this paper I claim that the referential status of that-clauses, along with their adjunct/argument status can account for patterns of $w h$-extraction, main clause phenomena and complementizer drop in different types of that-clauses. Specifically, I claim that MoSCCs, NCCs and that-clauses associated with the pronoun it are referential modifiers, factive that-clauses are (often) referential complements (they sometimes can be non-referential) and non-factive thatclauses are non-referential complements. I argue that these different classifications correlate with different syntactic behavior associated with each type of that-clause; specifically, the availability of wh-extraction, main clause phenomena and complementizer drop. My goal is to provide a clearer typology of that-clauses which appear with factive verbs, non-factive verbs, manner-ofspeaking verbs, nouns, and the pronoun it, based on their referential/non-referential and adjunct/argument status.

The paper is organized as follows. In Section 2, I present an overview of the data patterns in more detail, then focus on specific patterns in Sections 3-6. Section 3 focuses at factive and non-factive complement clauses, Section 4 noun complement clauses, Section 5 manner-ofspeaking clauses and Section 6 it-clauses (a.k.a. object extraposition constructions). Section 7 examines some differences between factive and semifactive clauses and Section 8 concludes the discussion.

2. Data patterns in more detail. In this section I present the relevant data patterns, starting with complement clauses to non-factive and factive verbs. The phenomena I examine are the availability of wh-extraction, main clause phenomena (MCP), specifically argument fronting, and complementizer drop (C-drop). As illustrated below, non-factive verb complement clauses (VCCs) allow extraction of both arguments (5a) and adjuncts (5b), allow MCP (6), and allow Cdrop (7).

(5) Non-factive VCC: No Island effects

a. Who does Mary think that she saw $t$ ?

b. When did Mary think that John saw Phil $t$ ?

(6) Non-factive VCC: MCP allowed

a. John thinks that this book Mary read $t$.

b. Mary claimed that this book, John read $t$.

(7) Non-factive VCC: C-drop allowed

a. John thinks (that) Mary read this book.

b. Mary claimed (that) John read this book.

In contrast, factive VCCs are weak islands for extraction, allowing argument extraction (8a), but not adjunct extraction (8b). Factive VCCs also resist MCP (9), and C-drop (10).

\section{Factive VCC: Weak Island}

a. Who does Mary regret that she saw $t$ ?

b. *When did Mary regret that John saw Phil $t$ ? 


\section{(9) Factive VCC: Resists MCP}

a. (Haegeman 2012:257, citing Maki et al. 1999:3)

* John regrets that this book Mary read $t$.

b. (Haegeman 2012:257 citing Hegarty 1992:52, note 19)

* Mary realizes that this book, John read $t$.

(10) Factive VCC: Resists C-drop

a. John regrets *(that) Mary read this book.

b. Mary loves *(that) John read this book.

The behavior of so-called noun complement clauses (NCCs) differs from both non-factive VCCs and factive VCCs in extraction. ${ }^{2}$ NCCs are strong islands for extraction, with both argument extraction (11a), and adjunct extraction (11b), degraded. NCCs, like factive VCCs, resist MCP (12), and C-drop (13).

\section{(11) NCC: Strong Island}

a. * Which man did John believe rumors that Mary kissed $t$ ?

b. *When did Mary believe the claim that John saw Phil $t$ ?

(12) NCC: Resists MCP

a. (Haegeman 2012:258, citing Hooper \& Thompson 1973:479)

* I resent the fact that each part he had to examine $t$ carefully.

b. (Haegeman 2012:258, citing Emonds 2004:77, note 3)

* A promise that defective sets the company will fix $t$ has been made by John.

\section{(13) NCC: Resists C-drop}

a. I resent the fact *(that) he had to examine each part carefully.

b. A promise *(that) the company will fix defective sets has been made by John.

Manner-of-speaking that-clauses show the same pattern as NCCs, despite the fact that they are non-factive. They are strong islands for extraction (14), resist MCP (15), and resist C-drop (16) (for discussion see Zwicky 1971; Erteschik-Shir 1973, 2006; Stowell 1981; Snyder 1992, Ambridge \& Goldberg 2008; Stoica 2016; among others). This is surprising, as we might expect them to behave like other non-factive VCCs.

\section{(14) MoSCC: Strong Island}

a. *Who did Mary whisper that John met $t$ ?

b. (Cinque 1990)

?? How $i$ did you murmur that John kissed Mary $\mathrm{t}_{i}$ ?

\section{(15) MoSCC: Resists MCP}

a. * John whispered that this book Mary read $t$.

b. *I groaned that the pizza, John ate $t$.

(16) MoSCC: Resists C-drop

a. John whispered *(that) you didn't come to the party.

b. Martin groaned *(that) the TV was broken.

\footnotetext{
${ }^{2}$ I say "so-called” because I analyze NCCs (as well as MoSCCs and ICCs) as adjuncts, not complements.
} 
Finally, that-clauses following the pronoun it (ICCs) (a.k.a. object extraposition constructions) show the same behavior as NCCs and MoSCCs. They are strong islands for extraction (17), resist MCP (18), and resist C-drop (19).

\section{(17) ICC: Strong Island}

a. * Who did Mary regret it that John met $t$ ?

b. * Why did Mary resent it that John kissed Mary $t$ ?

(18) ICC: Resists MCP

a. * John resents it that this book Mary read $t$.

b. * Maria loves it that the big prize John won $t$.

(19) ICC: Resists C-drop

a. John resents it *(that) you didn't come to the party.

b. Maria believes it*(that) the company will fix defective sets.

Table 1 summarizes the data in this section. Note that NCCs, MOSCCs and ICCs share the same behavior, while factive VCCs differ from these only in extraction (weak vs. strong). In Sections 3-6 I will discuss each of these types of that-clause in more detail and provide an analysis for each, beginning with non-factive and factive VCCs in section 3.

\begin{tabular}{l|l|l|l|l|l} 
& $\begin{array}{l}\text { Non-factive } \\
\text { VCC }\end{array}$ & $\begin{array}{l}\text { Factive } \\
\text { VCC }\end{array}$ & NCC & MoSCC & ICC \\
\hline Island & No & Weak & Strong & Strong & Strong \\
Resist MCP & No & Yes & Yes & Yes & Yes \\
\hline
\end{tabular}

\section{Table 1: Data Summary}

3. Non-factive and factive VCCs. Recall from Section 2 that non-factive and factive VCCs display different behavior. Non-factive VCCs allow extraction of arguments and adjuncts, allow MCP and allow C-drop (5-7). Factive VCCs are weak islands for extraction and resist MCP and C-drop (8-10). Following the analysis in de Cuba \& Ürögdi (2009) and de Cuba (2017), I claim that referentiality should replace factivity as the relevant notion surrounding the behavior of thatclauses. In this view, CPs are referential by default and non-referentiality is signaled by the merger of additional structure. Referential complement clauses are truncated structures as opposed to non-referential complement clauses (20).
a. Referential CP: V
b. Non-referential $c \mathrm{P}: \mathrm{V}$
$[\mathrm{CP}]$
$[\mathrm{CP}]]$

These structures are exploited to account for differences between factive and non-factive VCCs. For de Cuba \& Ürögdi (2009), adjunct extraction and MCP are blocked in referential VCCs due to this truncation. Specifically, the presence of non-referential $c \mathrm{P}$ facilitates $\mathrm{MCP}$ (due to the extra syntactic position) and extraction of adjuncts (due to the non-referential status of the clause 
conferred by $c \mathrm{P}) .^{3}$ Building off this work, de Cuba (2017) provides the following definitions for referential and non-referential CPs (see also de Cuba \& Ürögdi 2009; Haegeman \& Ürögdi 2010; de Cuba \& MacDonald 2013; as well as 'main point of the utterance' proposed in Wiklund et al. 2009, following Simons 2007).

(21) a. Referential CP: an accepted (or pre-established) proposition in the existing discourse which has no illocutionary force.

b. Non-referential $c \mathbf{P}$ : a speech act which introduces a proposition (or an open question) which is not yet accepted (or pre-established) in the existing discourse.

Regarding C-drop, de Cuba (2017) makes the observation that referential complement clauses as a class resist $\mathrm{C}$-drop. ${ }^{4}$

To summarize, following de Cuba \& Ürögdi (2009) and de Cuba (2017), I abandon the factive/nonfactive distinction between VCCs in favor of a referential/non-referential distinction. Truncated referential CPs block MCP and extraction of adjuncts, accounting for the ungrammaticality of (8b) and (9), while referential CPs as a class resist C-drop, accounting for (10). In contrast, the extra structure in non-referential CPs facilitates $w h$-extraction (5) and MCP (6), while non-referential $c$ Ps as a class allow C-drop (7). In the next section I turn to NCCs.

4. NCCs as Referential Modifiers. In de Cuba (2017), following Hawkins (1978) and Mikkelsen (2014), I claim that NCC constructions are "referent-establishing" and involve close apposition. Hawkins (1978) and Mikkelsen (2014) observe that close nominal apposition structures like (22) have an intuitive similarity to NCCs like (23).

(22) the physicist Melissa Franklin

(23) the claim/fact that the government lied to the press

Mikkelsen (2014) shows that direct structure NCCs like (23) are like close nominal apposition structures (22) in that a CP like that the government lied to the press in (23) provides the primary semantic content of the noun claim (cf. Moulton 2015), just like the proper name Melissa Franklin in (22) provides the primary semantic content for the noun physicist. ${ }^{5}$ Note that in these cases content nouns like claim, fact and physicist have the unusual property that they can be felicitously uttered with a definite article at first-mention (24). However, the modifier is obligatory (25). (data from Hawkins 1978:147; see also Keizer 2007)

(24) a. I don't like the color red.

b. I can't stand the name Algernon.

${ }^{3}$ See Szabolcsi \& Zwarts (1993), who argue that there can be no variable left unbound within a referential complement, ruling out extraction of non-referential extractees and giving 'factive' complements (referential complements in the present proposal) their weak island status. See also Szabolcsi (2006) for discussion of referentiality and weak islands. For details on the effects of truncation see de Cuba \& Ürögdi (2009) and de Cuba (2017).

${ }^{4}$ As it stands this is simply a generalization. I leave a fleshed out analysis of why this generalization might hold to future work.

${ }^{5}$ Mikkelsen (2014:1), following Hankamer \& Mikkelsen (2012), divides Danish NCCs between 'relational structures', which involve a preposition (i) and 'direct structures', which do not (ii).

(i) [Relational structure: N P CP]

(ii) [Direct structure: N CP]

For Hankamer \& Mikkelsen (2012), relational structures are anaphoric, and direct structures are referent-establishing. For details the different properties of these constructions in Danish and English, see Mikkelsen (2014) and Hankamer \& Mikkelsen (2012). 
(25) a. \# I don't like the color.

b. \#I can't stand the name.

The same holds for content nouns like fact and conclusion in NCCs, as in (26) and (27).

(26) a. Bill is amazed by the fact that there is so much life on earth.

b. The man came to the conclusion that language did not exist.

(27) a. \#Bill is amazed by the fact.

b. \#The man came to the conclusion.

Hawkins argues that in both of the sets of constructions in (24) and (26) the modifier, "takes over the role of previous discourse, and enables the hearer to identify some set of objects within which he is to locate the referent." (Hawkins 1978:148). Keizer (2005) also discusses the discourse functions of close appositions, such as the 'descriptively identifying use' in which, "...the descriptive element provides information which allows the hearer to relate the referent of the construction as a whole to her 'knowledge base', or, more specifically to anchor the referent in the discourse situation" (Keizer 2005:449). In regards to close apposition in general, Keizer (2007) concludes that, "...the whole point in using an apposition consists in the fact that through the combination of a proper noun and a descriptive element one can produce a referring expression which is felicitous in a given context" (Keizer 2007:60). I take this as support for the idea that the "modifying" CP in NCC constructions is referential, and thus should share syntactic behavior with other referential clauses. NCCs always have an antecedent in the discourse. In other words, the content noun (claim, fact, etc.) and its associated CP refer to the same entity. The claim is that in this all NCCs are referential as they are co-referential with their content noun, as in (28). Following the definitions in (21), NCCs are referential. It is clear that the propositions in (29) do not have illocutionary force. ${ }^{6}$

(28) the $[\mathrm{N} \text { claim/fact }]_{i}[\mathrm{CP} \text { that the government lied to the press }]_{\mathrm{i}}$

(29) a. the claim that John left

b. the belief that the earth is flat

Typically, an assertion is defined as a speech act in which the speaker puts forth a proposition as being true (i.e. to be included in the common ground). Krifka (2014) takes the view that in an assertion, the speaker takes on the social commitment that the content of the assertion is true. By this definition, the NCCs in (29) are not asserted (since they can be uttered felicitously by a speaker without any commitment to the truth of the proposition). Krifka $(1999,2014)$ claims that there are sentence radicals, which denote propositions, and speech acts, which are formed when illocutionary operators are applied to sentence radicals. He notes that sentence radicals have more syntactic restrictions, citing examples of MCP being restricted to contexts where they follow predicates that typically allow associated clauses with illocutionary force operators. For my purposes here, referential CPs can be equated to sentence radicals, and non-referential $c$ Ps speech acts.

\footnotetext{
${ }^{6}$ While it is clear that NCCs do not have illocutionary force, one might still question how NCCs (as well as MoSCCs and ICCs to be discussed below) are "accepted" or "established" in the discourse when they can be uttered outof-the-blue, and thus not be in the previous discourse. However, I follow the idea that these constructions are referent-establishing (see Mikkelsen 2014:10 and Hankamer \& Mikkelsen 2012, who follow in the spirit of Hawkins 1978:130-149), so they qualify as established in the discourse.
} 
As noted above in (8-13) (repeated below with "factive" changed to "referential"), NCCs show similar syntactic behavior to referential VCCs when it comes to resisting MCP $(9,12)$ and C-drop $(10,13)$. However, they differ when it comes to island status: Referential VCCs are weak islands (8) and NCCs are strong islands (11).

(8) Referential VCC: Weak Island

a. Who does Mary regret that she saw $t$ ?

b. *When did Mary regret that John saw Phil $t$ ?

(9) Referential VCC: Resists MCP

a. (Haegeman 2012:257, citing Maki et al. 1999:3)

* John regrets that this book Mary read $t$.

b. (Haegeman 2012:257 citing Hegarty 1992:52, note 19)

* Mary realizes that this book, John read $t$.

(10) Referential VCC: Resists C-drop

a. John regrets *(that) Mary read this book.

b. Mary realizes *(that) John read this book.

(11) NCC: Strong Island

a. * Which man did John believe rumors that Mary kissed $t$ ?

b. *When did Mary believe the claim that John saw Phil $t$ ?

(12) NCC: Resists MCP

a. (Haegeman 2012:258, citing Hooper \& Thompson 1973:479)

* I resent the fact that each part he had to examine $t$ carefully.

b. (Haegeman 2012:258, citing Emonds 2004:77, note 3)

* A promise that defective sets the company will fix $t$ has been made by John.

(13) NCC: Resists C-drop

a. I resent the fact * (that) he had to examine each part carefully.

b. A promise *(that) the company will fix defective sets has been made by John.

I have claimed above that referential CPs are truncated structures, lacking the structure needed for MCP. Since both referential VCCs and NCCs are referential, the lack of MCP is expected (9), (12). I have also claimed that referential CCs as a class resist C-drop, so C-drop in referential VCCs (10) and NCCs (13) is also expected. So what causes the difference in extraction between referential VCCs (weak islands) and NCCs (strong islands)? For this difference, the proposal in de Cuba (2017) that close apposition involves adjunction provides the explanation for the strong island status of NCCs (11): adjuncts are strong islands for extraction (see Stowell 1981, Snyder 1992, among others). ${ }^{7}$ In contrast, referential VCCs are complements. Their referential status

7 There is some disagreement in the literature regarding the strong island status of MoSCCs (see Ambridge \& Goldberg 2008; Szabolcsi 2006; Erteschik-Shir 1973; Stowell, 1981). In addition, Dor (2005) claims that complementizer drop is possible with some MoSCCs. See Stoica (2016) for discussion. Stoica proposes that MoSCCs that allow extraction and complementizer drop have two lexical entries, one which has a strong manner component and the other which behaves like a communication verb (say, think) without a strong manner component. If the communication verb entry is selected then extraction and complementizer drop are allowed. I leave a more detailed discussion of these potential counterexamples to future work. 
blocks adjunct extraction, but arguments can extract, making them weak islands (8). Thus, the contrast is extraction between NCCs and referential VCCs is accounted for.

To summarize, following de Cuba (2017) I claim that NCCs are referential CPs. Thus, MCP (12) and C-drop are resisted. Finally, NCCs are strong islands because they are CP adjuncts (adjunct islands) (11). Next I extend the analysis of de Cuba (2017) to MoSCCs.

5. MoS that-clauses as referential modifiers. Like referential VCCs and NCCs, MoSCCs (1416 repeated here) resist MCP (15) and C-drop (16). In addition, like NCCs they are also strong islands (14).

(14) MoSCC: Strong Island

a. *Who did Mary whisper that John met $t$ ?

b. (Cinque 1990)

??How $i$ did you murmur that John kissed Mary $t_{i}$ ?

\section{(15) MoSCC: Resists MCP}

a. * John whispered that this book Mary read $t$.

b. *I groaned that the pizza, John ate $t$.

(16) MoSCC: Resists C-drop

a. John whispered *(that) you didn't come to the party.

b. Martin groaned *(that) the TV was broken.

In order to account for the similar behavior of NCCs and MoSCCs I propose the following:

MoSCCs behave like NCCs because they are referential in the same way as NCCs. The only difference is that MoSCCs modify a (usually null) content noun object, as in (30).

(30) Barney whispered [a whisper]i [that Wilma was dating Fred]i

In other words, NCCs and MoSCCs share the same structure, with the only difference being whether the content noun is null (MoSCCs) or overt (NCCs). ${ }^{8}$ Following de Cuba (2017), close apposition involves adjunction, providing an explanation for the strong island status of NCCs, as shown above in (11) (adjuncts are strong islands for extraction). MoSCCs are also strong islands (14), which is expected if they are adjuncts. As with NCCs, MoSCCs resist MCP (14), and Cdrop (16), because they are referential.

The present analysis of MoSCCs has predecessors in the literature. Zwicky (1971) proposed that MoS verbs have a cognate object, and Snyder (1992) analyzed MoSCCs as adjuncts (see also Stowell 1980; Moltmann 1989). For Snyder, a MoS verb like grunt has a syntactic representation as in (31). If grunt has a corresponding CP, Snyder claims it is in apposition to grunt, not a complement.

(31) (Snyder 1992:3)

[v (make)] [NP (a) [N grunt]]

Snyder also notes the similar behavior of NCCs and nominal apposition structures when it comes to blocking extraction, as illustrated in (32), where both are strong islands.

\footnotetext{
${ }^{8}$ The fact that the content noun is usually null fits well with Hale \& Keyser's (2002) analysis of cognate objects with unergatives like "dance", where the null object is licensed by the semantic content of the verb "dance" (see Hale \& Keyser 2002: Chapter 3). The same analysis can apply to the verb "whisper" licensing the null N "whisper" in (30).
} 
(Snyder 1992:2-3)

a. * Whom did John make a bold suggestion [that Mary likes $t$ ]?

b. *What did John say that Fred was [NP Frederick the Great], [NP King of $t$ ]?

Finally, Snyder reaches similar conclusions to those proposed here on the differences between the argument status of referential/non-referential VCCs vs. the adjunct/appositive status of NCCs and MoSCCs vs. VCCs, proposing that, "A verb takes a CP argument if and only if the verb attributes, to its subject or to the speaker, a propositional attitude towards the content of the CP." (Snyder 1992:4).

However, not everyone agrees with the adjunct analysis. For example, Kogusuri (2009) provides a few potential arguments against apposition, two of which I will take up here. First, Kogusuri notes that MoS verbs can take NP arguments, as in (33). Thus, they appear to dispense a theta-role for NPs, but it is not clear how the theta-role is dispensed when there is only a CP.
a. (Zwicky 1971:224)
Hoffman will probably mutter a foul oath/two or three words/something unintelligible.
b. John groaned a pained groan.

Second, Kogusuri notes that in some cases MoS that-clauses can be passivized, which would be unexpected if the $\mathrm{CP}$ were an adjunct. If the $\mathrm{CP}$ (linked to the expletive) can be passivized in (34), it is not behaving like an adjunct.

(34) (Kogusuri 2009:190)

a. It is whispered that he intended to resign.

b. ...it was shouted that they were bringing Kule in.

The present analysis provides possible solution for each of these objections. For (33), I have proposed that there is always an (often unpronounced) argument following MoS verbs (following Zwicky 1971). Therefore in my analysis a theta-role is dispensed in both cases, either to a null or pronounced content noun. For (34), my analysis provides the possibility that the argument content noun (in the form of $i t$ ) is passivized, not the adjunct $C P$, so passivization of the noun should in principle be possible.

To summarize this section, I have argued that MoSCCs, like NCCs, are referential CPs. MoSCCs, like NCCs, resist MCP (15), because they are referential CPs (no $c \mathrm{P}$ position for MCP movement). MoSCCs, like NCCs, block C-drop (16), because referential CPs as a class block Cdrop. MoSCCs, like NCCs, are strong islands (14), because they are CP adjuncts (adjunct islands). Next we look at another construction that behaves the same as NCCs and MoSCCs, namely ICCs.

6. It + that-clause (ICC). Another construction that can be analyzed as case of close apposition is the $i t+$ that-clause construction (ICCs). These are also referred to in the literature as "object extraposition" or "anticipatory it". In these constructions a complement clause is anticipated by the pronoun it. In a discussion of these constructions, Gentens (2016) characterizes the anticipatory it and the that-clause that follows it as being co-referential (as I've claimed for content 
nouns and their associated that-clauses in NCC and MoSCC constructions). Here I follow Gentens in focusing specifically only at the cases where the anticipatory it appears in object position and is optional, as in (35). ${ }^{9}$

(35) a. I resent (it) that he never gives me credit.

b. I love (it) that they moved in across the street.

ICCs display a familiar resistance to extraction (17), MCP (18) and C-drop (19) (17-19 repeated here). This is the same as MoSCCs and NCCs.

\section{ICC: Strong Island}

a. * Who did Mary regret it that John met $t$ ?

b. * Why did Mary resent it that John kissed Mary $t$ ?

(18) ICC: Resists MCP

a. * John resents it that this book Mary read $t$.

b. * Maria loves it that the big prize John won $t$.

(19) ICC: Resists C-drop

a. John resents it *(that) you didn't come to the party.

b. Maria believes it *(that) the company will fix defective sets.

Given these similarities it is natural to give ICCs the same apposition analysis as I proposed for NCCs and MoSCCs. In this case, instead of a content noun, the referential CP is in apposition to the pronoun it in object position. The referential status of $i t$ in these constructions, though controversial in the literature, receives support from Kaltenböck (2003), who argues that the it in extraposition constructions retains, "at least some of the referential force of a referring it, which allows it to establish a referential link with some clausal constituent in the context" (Kaltenböck 2003:253; see also Bolinger 1973, 1977; Pesetsky 1995). I propose that this exactly the same type of referential link that I have claimed occurs between the content noun its associated thatclause in NCCs and MoSCCs.

Finally, Note the extraction difference between the strong island ICC (36a), and NCC in (36b) as opposed to the weak island referential VCC in (36c).
a. * Who did Mary regret it that John met $t$ ?
b. *Who did Mary regret the fact that John met $t$ ?
c. Who did Mary regret that John met $t$ ?

The strong island status of (36b) is problematic for a Kiparsky \& Kiparsky (1971) style analysis that posits the presence of a silent 'fact' in order to account for the weak island status of factive VCCs. We might expect (36c) to be ungrammatical as well if it also contains 'the fact'.

7. A few comments on factives vs. semifactives. In Hooper \& Thompson's (1973) influential classification of complement taking verbs, semifactives (class E) seem to pattern with their true factives (class D) in resisting complementizer drop:

\footnotetext{
${ }^{9}$ I leave discussion of subject extraposition to future work. I also leave aside discussion of the interpretive differences between sentences with or without anticipatory it. See Gentens (2016) for one proposal on the interpretive difference.
} 

a. He said (that) he would leave.
(class A)
b. I thought (that) he would leave.
(class B)
c. He denied *(that) he had done it.
(class C)
d. He regretted *(that) he had done it.
(class D)
e. He discovered *(that) she had done it
(class E)

However, to my ear the facts are not so clear. While some semifactives do seem to resist complementizer drop, this is not always the case: for example the sentences in (38) seem fine to me with the complementizer omitted.

(38) a. I notice (that) you are wearing your class ring today.

b. You know (that) I always like to wake up early.

c. I was in my bedroom when I discovered (that) my wallet was gone.

The fact that semifactives (know, notice, discover, etc.) are less resistant to complementizer drop than true factives (regret, resent, love, etc.) mirrors difference in in the availability of MCP between the two classes (see Hooper \& Thompson 1973). In addition, Scandinavian languages are well known to allow V2 (another MCP) in the complements of semifactive verbs like discover, even with a factive interpretation ((39a) presupposes the truth of (39b)).
Swedish (Wiklund et al. 2009:1924-1925)
a. Vi upptäckte att den bloggen läste han inte varje dag. we discovered that that blog-the read he not every day 'We discovered that this blog he didn't read every day.'
b. Han läste inte den bloggen varje dag. he read not that blog-the every day 'He didn't read this blog every day.'

I have argued in previous work (de Cuba \& Ürögdi 2009, de Cuba 2017) that referentiality is the relevant notion for different syntactic behavior between the classes of complement clause, not factivity, so a difference in behavior between true factives (class D) and semifactives (class E) is not unexpected. The prediction made by the present analysis is that MCP and C-drop should be possible in non-referential semifactive contexts. The difference then between semifactives (class E predicates) and true factives (class D predicates) then is that while both are factive, semifactives can more easily introduce a new (non-referential) proposition into the discourse that true factives, which tend to make a comment on an existing (i.e. referential) proposition.

8. Conclusion. In this paper I have claimed that the referential/non-referential and adjunct/argument status of that-clauses which follow factives, non-factives, MoS verbs, nouns and 'it' can account for the different patterns of $w h$-extraction, MCP and C-drop availability in these embedded clauses. My hope is to provide a more unified view of types of that-clauses than previous analyses have managed, and to bring less discussed that-clause types (NCCs, MoSCCs and ICCs) under the light of examination.

\section{References}

Ambridge, Ben \& Adele E. Goldberg. 2008. The island status of clausal complements: Evidence in favour of an information structure explanation. Cognitive Linguistics 19(3): 349-

381. https://doi.org/10.1515/COGL.2008.014.

Bolinger, Dwight. 1977. Meaning and Form. London: Longman. 
Bolinger, Dwight. 1973. Ambient "it” is meaningful too. Journal of Linguistics, 9(2), 261-270. https://doi.org/10.1017/S0022226700003789.

Cinque, Guglielmo 1990. Types of A'-Dependencies. Cambridge, MA: MIT Press.

de Cuba, Carlos. 2017. Noun complement clauses as referential modifiers. Glossa: A Journal of General Linguistics. DOI: http://doi.org/10.5334/gjgl.53.

de Cuba, Carlos and Jonathan MacDonald. 2013. Referentiality in Spanish CPs. In Victoria Camacho Taboada, Ángel Jiménez Fernández, Javier Martín González \& Mariano Reyes Tejedor (eds.), Information Structure, Agreement and CP, 117-140. Linguistik Aktuell: 197, John Benjamins. 10.1075/la.197.04cub.

de Cuba, Carlos \& Barbara Ürögdi. 2009. Eliminating factivity from syntax: Sentential complements in Hungarian. In Marcel den Dikken \& Robert Vago (eds.), Approaches to Hungarian Vol. 11, 29-64. John Benjamins. 10.1075/atoh.11.03cub.

Dor, Daniel. 2005. Toward a semantic account of that-deletion in English. Linguistics 43(2): 345-382. https://doi.org/10.1515/ling.2005.43.2.345.

Emonds, Joseph. 2004. Unspecified categories as the key to root constructions. In: David Adger, Cécile De Cat \& Georges Tsoulas (eds.), Peripheries: syntactic edges and their effects. 75120. Dordrecht: Kluwer.

Erteschik-Shir, Nomi. 2006. Bridge Phenomena. In: Martin Everaert \& Henk van Riemsdijk (eds.), The Blackwell companion to syntax. Oxford: Blackwell. 284-294.

Erteschik-Shir, Nomi. 1973. On the nature of island constraints. PhD dissertation, Cambridge, MIT.

Gentens, Caroline. 2016. The discursive status of extraposed object clauses. Journal of Pragmatics, Volume 96. 15-31. https://doi.org/10.1016/j.pragma.2016.03.001.

Haegeman, Liliane. 2012. Adverbial Clauses, Main Clause Phenomena, and the Composition of the Left Periphery: The Cartography of Syntactic Structures, Volume 8. Oxford: Oxford University Press.

Haegeman, Liliane \& Barbara Ürögdi. 2010. Referential CPs and DPs: An operator movement account. Theoretical linguistics 36(2-3): 111-152. https://doi.org/10.1515/thli.2010.008.

Hale, Ken \& Samuel Jay Keyser. 2002. Prolegomenon to a Theory of Argument Structure. Number 39 in Linguistic Inquiry Monograph, Cambridge, Mass.: MIT Press.

Hankamer, Jorge \& Line Mikkelsen. 2012. CP Complements to D. Ms. UC Santa Cruz and UC Berkeley. http://linguistics.berkeley.edu/ mikkelsen/papers/CP_complements.pdf (Accessed March 26, 2016).

Hawkins, John A. 1978. Definiteness and indefiniteness: a study in reference and grammaticality prediction. London: Croom Helm.

Hegarty, Michael. 1992. Familiar complements and their complementizers: On some determinants of A'-locality. University of Pennsylvania: Unpublished manuscript.

Hooper, Joan, and Sandra Thompson. 1973. On the applicability of root transformations. Linguistic Inquiry 4. 465-497. http://www.jstor.org/stable/4177789.

Kaltenböck, Gunther. 2003. On the syntactic and semantic status of anticipatory it. English Language and Linguistics 7.2: 235-255. https://doi.org/10.1017/S1360674303001096.

Keizer, Evelien. 2007. Close appositions. In Evelien Keizer. 2007. The English Noun phrase: The Nature of Linguistic Categorization (Studies in English Language series), 22-60. Cambridge: Cambridge University Press.

Keizer, Evelien. 2005. The discourse function of close appositions. Neophilologus, 89(3): 447467. https://doi.org/10.1007/s11061-004-0963-9. 
Kiparsky, Paul \& Carol Kiparsky. 1971. Fact. In Danny D. Steinberg and Leon A. Jakobovits (eds.), Semantics: An interdisciplinary reader in philosophy, linguistics and psychology, 345-369. Cambridge: Cambridge University Press.

Kogusuri, Tetsuya. 2009. Manner of Speaking Verbs and Their Clausal Complements in English. Tsukuba English Studies 27: 187-203.

Krifka, Manfred. 2014. Embedding illocutionary acts. In Thomas Roeper \& Margaret Speas (eds.), Recursion: Complexity in cognition, 59-87. Springer International Publishing. See also 'Embedded Speech Acts.' Ms., Humboldt-Universität zu Berlin. http://amor.cms.huberlin.de/ h2816i3x/Publications/Krifka_EmbeddingSpeechActs.pdf (Accessed March 26, 2016).

Krifka, Manfred. 1999. Quantifying into question acts. In Tanya Matthews and Devon Strolovitch (eds.), SALT IX: Proceedings of Semantics and Linguistic Theory, 181-198. Department of Linguistics, Cornell University: CLC Publications. http://dx.doi.org/10.3765/salt.v9i0.2830

Maki, Hideki, Lizanne Kaiser \& Masao Ochi. 1999. Embedded topicalization in English and Japanese. Lingua 109: 1-14. https://doi.org/10.1016/S0024-3841(98)00055-2

Moltmann, Frederike. 1989. Nominal and Clausal Event Predicates. In Proceedings of the Regional Meeting of the Chicago Linguistics Society (CLS) 25, Dept. of Linguistics, Chicago University: Chicago

Mikkelsen, Line. 2014. Clausal complements to $\mathrm{N}$ in Danish. Paper presented at Workshop on the North Germanic Noun Phrase. Universitet i Tromsø. (Handout). http://linguistics.berkeley.edu/ mikkelsen/talks/Tromso_handout.pdf (Accessed Jan. 18, 2018).

Moulton, Kier. 2015. CPs: copies and compositionality. Linguistic Inquiry 46(2): 305-342. https://doi.org/10.1162/LING_a_00183

Pesetsky, David. 1995. Zero Syntax. Cambridge, Massachusetts: MIT Press.

Simons, Mandy. 2007. Observations on embedding verbs, evidentiality, and presupposition. Lingua 117(6). 1034-1056. DOI: https://doi.org/10.1016/j.lingua.2006.05.006

Snyder, William. 1992. Wh-extraction and the lexical representation of verbs. Cambridge, MA: MIT Ms. http://web.uconn.edu/snyder/papers/Snyder_1992_Wh_V.pdf (Accessed Jan. 18, 2018).

Stoica, Irina. 2016. Island effects and complementizer omission: the view from manner of speaking verbs. In: Petronia Petrar \& Amelia Precup (eds.), Constructions of Identity (VIII): Discourses in the English-Speaking World. Cluj-Napoca, România: Presa Universitară Clujeană. 191-200. http://www.editura.ubbcluj.ro/bd/ebooks/pdf/2036.pdf

Stowell, Tim. 1981. Origins of phrase structure. Cambridge, MA: Massachusetts Institute of Technology dissertation.

Szabolcsi, Anna. 2006. Strong vs. weak islands. In: Martin Everaert \& Henk van Riemsdijk (eds.), The Blackwell Companion to Syntax, Vol. IV: 479-532. Blackwell.

Szabolcsi, Anna \& Frans Zwarts. 1993. Weak islands and an algebraic semantics for scope taking. Natural Language Semantics 1: 235-284. https://doi.org/10.1007/BF00263545

Reprinted In Anna Szabolcsi (ed.), Ways of Scope Taking, 217-262. Dordrecht: Kluwer.

Wiklund, Anna-Lena, Kristine Bentzen, Gunnar Hrafn Hrafnbjargarson and Porbjörg Hróarsdóttir. 2009. On the distribution and illocution of V2 in Scandinavian that-clauses. Lingua 119. 1914-1938. https://doi.org/10.1016/j.lingua.2009.03.006

Zwicky, Arnold M. 1971. In a manner of speaking. Linguistic Inquiry, 2(2). 223-233. http://www.jstor.org/stable/4177626 